\title{
Surgical Management of Breast Cancer under Local Anaesthesia: A Surgeon's Perspective
}

\author{
Tapesh Kumar Paul ${ }^{1}$, AR Chowdhury ${ }^{2}$, Russel Ahmed Khan Lodi ${ }^{3}$, Shayda Ali ${ }^{4}$ \\ Mohammad Arman Zahed Basunia ${ }^{5}$, Hasan Md. Abdur Rouf ${ }^{6}$
}

\begin{abstract}
Background: Treatment of breast cancer without surgery may not be effective. But in elderly patients with lots of co-morbidities, surgical management often cannot be done due to the significant risks of general anesthesia. The need for a safe, easy and effective alternative anaesthetic technique that can provide adequate peroperative analgesia as well as reduced anxiety in such group of patients was the main indication for this study. Materials and method: This prospective study was done on eleven patients, with coexisting medical conditions and who were not at all fit for general anaesthesia, and underwent breast cancer surgery under local anaesthesia. The patients were studied with regard to intraoperative analgesia, haemodynamic stability and complications related to technique. The study was done in Delta Medical College Hospital, Dhaka, Bangladesh. Results: Mean \pm SD of study patients were $64.7 \pm 7$ years old and all were suffering from coexisting medical conditions. Following local anaesthesia, mean intraoperative heart rate was $81.5 \pm 11.8$ beats/min and the mean blood pressure was 127.3/79 $\pm 9.6 / 7.0 \mathrm{mmHg}$. Patients felt no pain after infiltration of local anaesthetics, but experienced it if any place was missed before dissection. No complication occurred due to this procedure. All the candidates were fully satisfied with the procedure. Conclusion: Local anaesthesia provides satisfactory pain control along with keeping haemodynamics stable for surgical treatment of breast cancer among elderly patients having co-morbid conditions.
\end{abstract}

Keywords: Breast cancer; elderly patients; co-morbities; breast surgery; mastectomy; local anaesthesia; Lidocaine; analgesia.

Delta Med Col J. Jul 2017;5(2):63 - 67

\section{Introduction}

Along with breast cancer, a few patients present with some coexisting health conditions and consultants have to face difficulties to treat such kind of patients. Over recent decades, there have been significant advances in general anaesthesia. But surgery in the elderly and in patients with

1. Associate Professor, Dept. of Surgery, Delta Medical College, Dhaka, Bangladesh.

2. Assistant Professor, Dept. of Radiotherapy, Delta Medical College, Dhaka, Bangladesh.

3. Resident Surgeon of Surgery, Delta Medical College, Dhaka, Bangladesh.

4. Registrar of Surgery, Delta Medical College, Dhaka, Bangladesh.

5. Registrar of Surgery, Delta Medical College, Dhaka, Bangladesh.

6. Professor \& Head, Dept. of Surgery, Delta Medical College, Dhaka, Bangladesh.

Correspondence: Dr. Tapesh Kumar Paul. e-mail: tapeshpaul@yahoo.com 
significant medical problems still has substantial morbidity and mortality. Local anaesthesia has been steadily refined since its introduction by Koller in $1884 .{ }^{1}$ A number of authors have described the use of local anaesthesia for more major procedures ${ }^{2-4}$, but in general these techniques were employed because of necessity rather than choice. This not only avoids the risks and unpleasantness which are sometimes associated with general anaesthesia, but may also provide specific benefits such as reduced blood loss, better post-operative analgesia, shorter hospital stay and cost reduction. ${ }^{5}$

In this study we aimed to assess the feasibility of local anaesthesia in breast cancer surgery in those patients who were unfit for general anaesthesia. We describe a safe and simple technique for the performance of simple mastectomy or breast conservative surgery with or without axillary dissection under local anaesthesia allowing the patient to receive optimum treatment.

\section{Materials and method}

All diagnosed breast cancer patients from the year 2008 to 2015 were assessed physically and then relevant investigations were done. Patients, who were declared as unfit by anaesthesists or not willing to go for surgery under general anaesthesia due to significant risks described by anaesthesists, were offered surgery under local anaesthesia. Proper counseling of the patients were done to reduce anxiety and to build confidence. Day before surgery, patients were allowed to take anxiolytic drug at night. Before starting surgery both narcotic and non-narcotic analgesics were given through parenteral route. During procedure, $2 \%$ Lidocaine HCL USP with $0.0005 \%$ Epinephrine USP was used.

\section{Results}

Total 11 cases of cytologically proven breast cancer patients underwent surgery under local anaesthesia from the period 2008 to 2015 (Table 1).

All the patients were between the ages of 52 and 77 years; the mean age of patients was 64.7 years (SD, 7 years). The tumour stages were T1 (01) and T2 (10). All patients were suffering from one or more coexisting medical conditions including ischemic heart disease, cardiomyopathy with very low ejection fraction, multiple valvular disease, atrial fibrillation, bronchial asthma, chronic bronchitis, lung fibrosis, diabetes mellitus, renal impairment, cerebrovascular accident and severe post chemotherapy complications.

Among the patients, six underwent lumpectomy and five had mastectomy. Axillary dissection was done in five of the 11 patients. Apart from pain during infiltration of local anaesthesia and in some places of neurovascular innervations which was not identified earlier, overall method was successful in producing adequate anaesthesia and allowed the performance of the surgery without significant deviations from usual technique in all patients. The time taken for the performance of the procedure (anaesthesia plus surgery) was no longer than that of conventional general anaesthesia plus surgery and the average time was 62.7 minutes (range, 30 to 90 minutes). The total volume of Lidocaine mixed with epinephrine required for surgery was less than $7.0 \mathrm{mg} / \mathrm{kg}$.

During the procedure, patients' mean heart rate was $81.5 \pm 11.8$ beats $/ \mathrm{min}$ and the mean blood pressure was 127.3/79 $\pm 9.6 / 7.0 \mathrm{~mm}$ of $\mathrm{Hg}$. Oxygen saturation did not deviate from that existed preoperatively with the patients. Peroperative blood loss was low in all patients and collection from drain tube did not exceed more than $300 \mathrm{~mL}$ in any patient. There was no surgical haematomas of the resected site, which would require needle drainage. There was also no surgical morbidity in terms of wound infections, necrosis of skin flaps and no side effects of Lidocaine. 
Table I: Information of patients and procedure

\begin{tabular}{|c|c|c|c|c|c|c|c|c|c|c|c|}
\hline No & $\begin{array}{l}\text { Age } \\
\text { in } \\
\text { Years }\end{array}$ & $\begin{array}{c}\text { Co- } \\
\text { morbidities }\end{array}$ & $\begin{array}{c}\text { T- } \\
\text { stage }\end{array}$ & Surg. Done & $\begin{array}{l}\mathbf{L A} \\
(\mathbf{m g} \\
/ \mathbf{k g})\end{array}$ & $\begin{array}{l}\text { Time } \\
\text { req. } \\
\text { (min) }\end{array}$ & $\begin{array}{c}\text { Pulse } \\
\text { (beats/min }\end{array}$ & $\begin{array}{c}\text { BP } \\
(\mathbf{m m} \text { of } \\
\text { Hg) }\end{array}$ & $\begin{array}{c}\text { Seroma } \\
(\mathrm{mL})\end{array}$ & His topath. & $\begin{array}{l}\text { Lymph } \\
\text { node }\end{array}$ \\
\hline 1 & 66 & $\mathrm{MVD}, \downarrow \mathrm{EF}$ & II & Lumpectomy & 3.3 & 45 & 76 & $140 / 86$ & 73 & Inves DCC & - \\
\hline 2 & 70 & $\downarrow \mathrm{EF}, \mathrm{AF}$ & II & Lumpectomy & 3.0 & 39 & 90 & $130 / 85$ & 68 & Inves DCC & - \\
\hline 3 & 52 & $\begin{array}{l}\text { Asthma, } \\
\text { DM, LF }\end{array}$ & II & Lumpectomy & 3.7 & 35 & 88 & $120 / 80$ & 90 & Inves DCC & - \\
\hline 4 & 72 & $\overline{D M}, \mathrm{CM}$ & 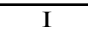 & Lumpectomy & 3.0 & 30 & 96 & $140 / 70$ & 50 & Inves DCC & - \\
\hline 5 & 60 & $\begin{array}{c}\mathrm{CB}, \mathrm{LF}, \\
\downarrow \mathrm{EF}\end{array}$ & II & Mastectomy & 5.2 & 70 & 70 & $110 / 70$ & 140 & Inves DCC & - \\
\hline 6 & 65 & $\begin{array}{c}\downarrow \mathrm{EF}, \text { Old } \\
\text { MI }\end{array}$ & II & Lumpectomy & 3.3 & 40 & 96 & $130 / 75$ & 75 & Inves DCC & - \\
\hline 7 & 63 & $\downarrow \mathrm{EF}, \mathrm{MVD}$ & II & $\begin{array}{c}\text { Mastectomy, } \\
\text { AD }\end{array}$ & 6.5 & 88 & 94 & $124 / 73$ & 195 & Inves DCC & 08 \\
\hline 8 & 58 & $\begin{array}{l}\perp \mathrm{EF}, \mathrm{CVD} \text {, } \\
\mathrm{IHD}, \mathrm{DM}\end{array}$ & II & $\begin{array}{c}\text { Lumpectomy } \\
\text {, AD }\end{array}$ & 6.3 & 85 & 74 & $117 / 77$ & 160 & Inves DCC & 11 \\
\hline 9 & 61 & $\begin{array}{c}\text { Post CT } \\
\text { MOF, } \downarrow \text { EF } \\
\text { DM }\end{array}$ & II & $\begin{array}{c}\text { Mastectomy, } \\
\text { AD }\end{array}$ & 6.7 & 90 & 80 & $123 / 85$ & 275 & Lobular ca & 10 \\
\hline 10 & 77 & $\begin{array}{l}\downarrow \mathrm{EF}, \mathrm{CM}, \\
\mathrm{IHD}, \mathrm{DM}\end{array}$ & II & $\begin{array}{c}\text { Mastectomy, } \\
\text { AD }\end{array}$ & 6.1 & 88 & 68 & $137 / 91$ & 245 & Inves DCC & 14 \\
\hline 11 & 68 & $\begin{array}{c}\downarrow \mathrm{EF}, \text { Old } \\
\text { MI, CKD, } \\
\text { DM }\end{array}$ & II & $\begin{array}{c}\text { Mastectomy, } \\
\text { AD }\end{array}$ & 6.4 & 80 & 64 & $129 / 77$ & 210 & Inves DCC & 12 \\
\hline Mean & 64.72 & - & - & - & 4.86 & 62.7 & 81.45 & $\begin{array}{c}127.27 / 7 \\
9\end{array}$ & 143.73 & - & - \\
\hline SD & 7.0 & - & - & - & 1.59 & 24.7 & 11.83 & $9.6 / 6.98$ & 78.69 & - & - \\
\hline
\end{tabular}

* MVD- Multiple valvular disease, EF - Ejection fraction, AF- Atrial fibrillation, DM- Diabetes mellitus, LF- Lung fibrosis, CM- Cardiomyopathy, CB- Chronic bronchitis, AD- Axillary dissection, DCC- Duct cell carcinoma, post CT MOF-Post chemotheraphy multiorgan failure.

\section{Discussion}

Our study has shown satisfactory pain control using local anaesthesia for breast surgery among elderly breast cancer patients with co-morbities. The haemodynamics remained stable during the surgical treatment. Optimal counselling eased the anxiety and fear of the patients before and during the procedure. Knowledge of innervation was critical for successful pain free operations under local anaesthesia.

Studies systematically assessing breast cancer surgery under local anaesthesia are limited. A study by Joseph et al. showed findings similar to us and proved that surgery under local anaesthesia was safe for those patients who were with severe co-morbid conditions. ${ }^{6}$ Their study involved simple mastectomy in all cases. In our study, we used multiple procedures including lumpectomy, simple mastectomy, breast conservation and simple mastectomy with axillary lymphnode dissection.

We have found that knowledge of innervation is helpful to do successful pain free operation under local anaesthesia. The breast is supplied by the anterior and lateral cutaneous branches of the second to sixth intercostal and supraclavicular nerves, and their distribution is variable. ${ }^{7}$ Mastectomy is thus a difficult task to perform under local anaesthesia, especially when axillary node dissection is needed.

Elderly patients of breast cancer who have been suffering from one or more coexisting medical 
conditions like ischemic heart disease, cardiomyopathy with very low ejection fraction, atrial fibrillation, bronchial asthma, chronic bronchitis, lung fibrosis, diabetes mellitus, renal impairment, history of cerebrovascular accident etc. carry significant risks to undergo surgery under general anaesthesia. Moreover, after receiving chemotherapy, some breast cancer patients may develop cardio toxicity. It makes them more vulnerable to have operation under general anaesthesia. ${ }^{8}$

Our 11 study patients received optimal counselling before and after the surgical procedure. The surgical team needed to take extra care for anxiety and fear, pain, and positional problems of the patients. Lots of discussions had to be made about various understandings and concepts of the patients. Positive information about the procedure was constantly given to alleviate the anxiety. Extra sympathy had to be shown for pain, which was managed.

In this study, the day before the procedures, patients were allowed to take anxiolytic drug at night; both narcotics and NSAIDs were used just before the procedure. Narcotic analgesic along with analgesia created conscious sedation. Then circumferential infiltration of local anaesthesia was given and level of anaesthesia was checked. After that, the infiltration incision was made. Dissection was done usually by bipolar diathermy as it did not affect its surroundings, which could occur in case of unipolar diathermy. ${ }^{9}$

Infiltration of local anaesthetics was frequently required as neurovascular bundles came in the field. These could be detected by either direct visualization or pain reported by the patients. It was more during axillary dissection, where extra attention was required due to presence of great vessels as well as important neurovascular bundle. Other difficulties in axillary dissection were positioning on a sand bag with abducted shoulder and retraction of pectoral muscles which we minimized by keeping short time placement of sand bag and reduced retraction subsequently during axillary dissection.

Our techniques did not derange haemodynamic stability. During the procedure, the mean heart rate of patients was $81.5 \pm 11.8$ beats $/ \mathrm{min}$ and the mean blood pressure was $127.27 / 79 \pm 9.6 / 6.98 \mathrm{~mm}$ of $\mathrm{Hg}$. The oxygen saturation did not deviate from what were present earlier to operation. Comparing with general anaesthesia these vital signs were within the acceptable limit. ${ }^{10}$

In this study, total volume of Lidocaine mixed with epinephrine required for surgery was less than $7.0 \mathrm{mg} / \mathrm{kg}$, which did not reach toxic level. ${ }^{11}$ The patients also did not experience usual side effects like flushing, redness of the skin, bruising, bleeding at the site of application, etc. as well as over dose related effects like change of consciousness, fainting, irregular heartbeat or pulse, breathing problem, and stopping of the heart. ${ }^{12}$ It indicates that the procedure was safe for the patients.

The peroperative blood loss observed in our study was low due to use of epinephrine with local anaesthetics and diathermy, and meticulous dissection. Postoperative recoveries of all patients were good as because there was no surgical haematomas of the resected site requiring needle drainage. There was also no surgical complications including wound infections and necrosis of skin flaps.

Our small case-series does not provide sufficient evidence to establish a procedure for doing breast cancer surgery under local anaesthesia. More research is needed involving larger number of patients. Studies on breast cancer patients with multiple co-morbidities are warranted, as they carry significant risk in general anaesthesia. Identification of specific anatomical land marks to infiltrate local anaesthesia easily will be crucial for the success of the procedure. 


\section{Conclusion}

Operative management of breast cancer under local anaesthesia cannot be an alternative to surgery under general anaesthesia. Rather we can say that as because surgery plays the main and important role in the management of breast cancer, it can be considered under local anaesthesia for elderly patients having significant co-morbidities. More application of this procedure is needed on patients who are not fit for general anaesthesia. This will help establish the precise criteria and determine the efficacy as well as tolerability of this procedure.

\section{References}

1. Koller C. On the Use of Cocaine for Producing Anaesthesia on the Eye. Lancet. 1884;2(3197):990-92.

2. Caffee HH, Benfield JR. Data Favoring Biopsy of the Breast under Local Anaesthesia. Surgery, Gynecology \& Obstetrics. 1975;140(1):88-90.

3. Howard CB, Mackie IG, Fairclough J, Austin TR. Femoral Neck Surgery Using a Local Anaesthetic Technique. Anaesthesia. 1983;38:993-94.
7. Sarhadi NS, Shaw DJ, Lee FD, Souter DS. An Anatomical Study of the Nerve Supply of the Breast, Including the Nipple and Areola. Br J Plast Surg. 1996;49(3):156-64.

8. Pai VB, Nahata MC. Cardiotoxicity of Chemotherapeutic Agents: Incidence, Treatment and Prevention. Drug Saf. 2000;22(4):263-302.

9. Ramsay JW, Shepherd NA, Butler M, Gosling PT, Miller RA, Wallace DM, A Comparison of Bipolar and Monopolar Diathermy Probes in Experimental Animal. Urol Res. 1985;13(2):99-102.

10. Oostrom JHV, Gravenstein C, Gravenstein JS. Acceptable Tanges for Vital Signs During General Anaesthesia. Journal of Clinical Monitoring. 1993;9(5):321-25

11. Medscape. Drugs \& Diseases; Lidocain anesthetic (Rx); Dosing \& Uses [Internet] [cited 2016 Aug 26]. Available from: http://reference.medscape.com/drug /xylocaine-zingo-lidocaine-anesthetic-343363.

12. Drugs.com. Lidocain Side Effects [Internet] [cited 2016 Aug 26]. Available from: http://www. drugs.com/sfx/lidocaine- side-effects. html. 